\title{
The University, Society, and Arms Control
}

\author{
KENNETH E. BOULDING \\ Department of Economics and Center for Research on Conflict Resolution, \\ University of Michigan
}

Arms control is a problem of social systems rather than of physical systems, even though physical systems such as weapons, satellites, and inspection devices may be deeply involved in it. A weapon, however, is not a physical thing-it is a physical thing in a social situation. The most innocuous object can become a weapon in the right social situation, and the most destructive device ceases to be a weapon if nobody wants to use it and nobody is afraid of it. It is to social systems, therefore, that we must look if we are to understand the arms race, and if we are to find out how to stop it and to reverse it.

As we look for light on this question it is useful to look at other social systems with the properties with which we are, perhaps, more familiar, and yet which exhibit in some degree the properties of the arms race. There is a striking analogy, for instance, between the problem of inflation and its control and the problem of the arms race and its control. Inflation is a disease of the price system in much the same way that the arms race is a disease of the threat system. In the price system it is only relative prices that are significant. If we were to double all wages and prices, for instance, the wage earner would not be any better off, and if the change were uniform throughout the system, which of course it never is, a rise in all prices and incomes in the same proportion would amount to little more than a change in the name that we give to a unit of money. Similarly, in what might be called the organized threat system as represented by the armed forces of the world, it is the relative sizes of these armed forces, and the relative threats which they represent to each other and to the people who pay for them, which constitute the essence of the system. In military terms it is only relative strength that is significant, not absolute strength. A nation increases its absolute strength by devoting a larger budget to its armed forces in the hope that this will increase its relative strength. If, however, its potential enemies perceive that their security is threatened by this, and they in turn increase their own armed forces, the relative positions may return to where they started. Nobody is any more secure absolutely, but everybody is worse off absolutely because resources are devoted to armaments which might have been devoted to other things. Just as an inflation frequently arises because the various groups in the society, including the government, are each trying to get a larger total sum of product for themselves than the total product permits, so an arms race arises when the various nations are trying to get more security for themselves at the expense of less security for others, and everybody wants more security in toto than the technological and political situation permits.

The hope for disarmament arises because 
it is clear that after an arms race has proceeded for some time, every nation participating in it would be better off absolutely, and would not be much changed in relative position, if the total amount spent on armed forces were very much reduced, as long as the distribution of the reduction is carefully arranged. There is clearly a bargaining situation here, in the sense that there is some position of the world in which everybody could be better off than he is now. It is this fact that a bargaining situation exists which makes the hope of disarmament so resilient, and explains why, in spite of all rebuffs and discouragements, the hope of disarmament refuses to die. Nevertheless, as everyone is aware, the achievement of the bargain is a matter of great difficulty. There have been one or two disarmament agreements in history but they have been rare. Here again the analogy with inflation may be helpful, though it should not be pushed too far. Inflation is an "easy" process because it gives all the parties a temporary illusion of being in a relatively better position. Deflation is a difficult and a painful process, so painful indeed that in our society it has become virtually impossible without severe social dislocation. Even the cessation of inflation in a society which has had a long one is a painful and difficult process. It is not, however, an impossible thing to do, and many societies have done it. Especially where people have become disgusted with the superficially attractive but bitter fruit of inflation, they have developed enough motivation and self-control to control it. Similarly, the arms race is easy, for each step gives the party that makes it an illusion of greater security. Arms control and disarmament are harder as they require longsightedness, self-control, and a higher level of social organization.

The distinction between arms control and disarmament has been stressed in some recent literature, but from the point of view of the dynamics of the world war industry, the distinction is a tenuous one. We may think perhaps of arms control as consisting of simply stopping the arms race so that we do not all make ourselves absolutely worse off. We may then perhaps think of disarmament as the process of actively and continually reducing the amount of economic resources spent on the world war industry so that we may all be absolutely better off. In both cases, however, it is the same system with which we are dealing. It is easier, perhaps, to achieve arms control than disarmament in the above sense, though even this may be questioned. If arms control is defined in the broad sense of T. C. Schelling, as a military cooperation with potential enemies, this represents a fundamental change from an uncontrolled and purely reactive system. The change in the international system implied in the shift from an uncontrolled arms race to a system of arms control is much more drastic than the change implied from a stabilized level of armaments to a declining one, and I suspect that if we can solve the first problem, it will be relatively easy to solve the second.

The political pressure for arms control, and beyond arms control for disarmament, arises, I suspect, from two sources. One is the sheer economics of the situation and the feeling that the $\$ 120$ billion a year which the human race spends on the world war industry is a shocking waste of resources which can ill be spared from more important tasks such as economic development. Anyone who is not ashamed of the fact that the world is spending $\$ 120$ billion a year on the means of destruction is in pretty poor standing as a human being and as a member of the crew of this overcrowded spaceship. This is a crucial period in the history of the 
planet; we now have a chance of achieving a stable high-level society on a world scale in which the major sources of human misery -hunger, poverty, and disease-will be eliminated. We may never eliminate unhappiness but we can at least eliminate misery! Our chance of doing this, however, is reduced by every dollar we spend on the war industry. Even in the affluent United States the war industry is a severe drain, especially on our intellectual and organizational resources, of which it absorbs a very large proportion, and our poor growth rate and our inability to solve many internal problems can largely be attributed to it.

The case for disarmament is further strengthened, however, when we ask what it is we are buying with this $\$ 120$ billion a year. The answer seems to be an increase in insecurity, fear, and an absolute diminution in the power of the larger states. When, after spending $\$ 500$ billion on defense in ten years, the armed forces of the United States have to turn around and say to the civilian population, "Dig your own holes, boys," it is obvious that something has gone radically wrong. Furthermore, when the fear of escalation makes it all but impossible for the United States to do anything in a military way about Cuba, and when, similarly, the Soviet Union cannot even handle Albania, it would seem again that something has gone radically wrong. It is the almost unconscious recognition of the depth of the crisis of the defense system which provides the steam for the movement towards arms control and disarmament. We are all looking for a form of national and personal security which will be less costly and more secure than what we have now. We are suffering from an enormous inflation of the defense system which has increased nobody's relative security, has diminished everybody's absolute security, and has likewise diminished everybody's absolute welfare.
This crisis of the defense system which we are now facing is, paradoxically enough, a result of the very inner dynamic of the armed forces themselves, particularly as expressed in research and development. It is hardly an exaggeration to say that the armed forces have researched themselves into obsolescence. It is the very fact that the arms race, since the end of the Second World War, has taken the form of a research and development race, almost as much as a quantitative expenditure race, that gives uniqueness to the present moment in history. We have never had a situation like this in which weapons development has been so divorced from the use of the weapons developed. As Herman Kahn has expressed it, if we count the development between the First and the Second World Wars as a "generation," we now go through a generation of development every three or four years. On this scale it is already too late for the third, or the fourth, or even the fifth world war. We are about ready for the sixth or the seventh. This means that the nations of the world are operating in a military system the properties of which they do not know, and it is this fact which gives the present moment its peculiar danger.

More than anything else, the collapse of the defense system is a result of the increase in the range of the deadly missile. I have pointed out in Conflict and Defense (Boulding, 1962) that the range of the deadly missile is the main factor determining the minimum size of the unconditionally viable defense organization. The longer the range of the deadly missile, the larger must be the organization which is to be successfully defended by it. We are now rapidly approaching the stage in which the range of the deadly missile is half the circumference of the earth, or 12,500 miles. This means that the only organization which can be defended by 
these instruments is mankind as a whole. We have, therefore, come to the end of a very long process and have reached a profound break in the continuity of history. Up to this point history has been a long process by which we have learned to increase the range of the deadly missile from that of David's slingshot through Alexander's armies (for an army itself can be thought of as a deadly missile) to the latest ICBM. This process has gone hand in hand with an increase in the minimum size of the unconditionally viable state, till now we have gotten to the point where the only unit that can be defended is mankind as a whole. We have come to the point, in other words, where war must be abolished and we must establish the institutions and habits of stable peace. The search for negotiated arms control and disarmament is only a part of this process, and perhaps not even the most important part. We achieved personal disarmament over a large part of the world by a combination of unlilateral decisions on the part of individuals as they developed skill in the handling of quarrels without weapons, reinforced by the establishment of law and order and a little second-strike capability in the hands of the sheriff. It may be that we shall get national disarmament also by a complex set of processes in which graduated unilateral disarmament, both reciprocated and unreciprocated, will play a part; in which the establishment of international organizations capable of interposing themselves between quarreling parties will also play a part; and in which military cooperation among potential enemies will also play a part. It is desirable that all these lines be pursued simultaneously with a concentrated intellectual effort applied to each.

The role of the universities, both in the smaller problem of bargaining for arms control and disarmament agreements and in the larger problem of establishing a stable peace, is likely to be central and crucial. The university is the only agency in society which is committed to the future rather than to the past, which is committed to mankind as a whole rather than to any segment of it, and which is committed to the truth rather than to any particular version of it. Universities as institutions have frequently fallen short of these ideals. In some cases they have been so wedded to the task of transmitting the heritage of the past that they have ceased to do effective research, and the development of knowledge, as in the early origins of science, has had to proceed largely outside their walls. This, fortunately, is no longer true of most universities, especially in this country, though there are still institutions in some parts of the world which are not very far removed from the condition, shall we say, of Oxford in the time of Adam Smith.

There are universities also, like those of Nazi Germany, which have prostituted themselves in the service of a single country or race. There is, indeed, a delicate balance to maintain here between a proper loyalty to the culture and the country in which the institution is located and that wider commitment to the human universe which the name university implies. Here again, I think we can take a modest satisfaction in our own achievements; the great universities of this country are no less American for being great world institutions, opening their resources with warmth and generosity to people of every land and race and taking all knowledge for their province.

Universities, as institutions, have not always been guiltless as an institution of committing themselves so deeply to some particular doctrine or vision of truth that they have been blind to new truth as it has arisen. Even in this country, we have our own 
orthodoxy and we persecute those who deny it in a thoroughly unsportsmanlike fashion. Our orthodoxy, however, is a broad and latitudinarian one. Our gate is so wide that the earnest searcher after truth hardly notices it and pursues his way unhampered. In this, too, we are more fortunate than most, and we have correspondingly the greatest responsibility.

The responsibility of the university is further underlined because, at the moment at least, the road to stable peace is blocked by sheer ignorance of how to attain it. A major part of the task of establishing stable peace, therefore, is an intellectual task which is peculiarly in the province of the university. This is the task of understanding the world social system and especially its immensely complex dynamic processes, for without understanding these processes our actions, however well intentioned, will inevitably be blind. We have a task before us also of establishing a system of information collection and processing by which images of the world social system, and especially of the international system, can be tested for reality. Operating agencies such as the State Department and the Department of Defense cannot be expected to do either the basic theoretical work or the work in developing an objective and scientific information processing system which will be necessary if we are to make the transition from the unstable peace in which we now live to the stable peace that we all hope for. Operating agencies are quite rightly preoccupied with day-to-day matters and concerned with operating the existing system rather than with searching for ways in which it may be improved.

Morton Kaplan distinguishes between what he calls the "task" and the "meta-task." The task is doing something which seems to be prescribed by the existing system; the meta-task is asking whether the task itself should be done or whether some other task should be substituted. Operating agencies of any kind have to concentrate on the best way of getting something done. The task is usually taken for granted because to question it would imperil the very operation itself. Operating agencies, therefore, are always in grave danger of concentrating all their energies on finding the best way of doing something which should not be done at all. This danger is particularly high in times of very rapid change in the social system, like the present. Under these circumstances, experience, and the wisdom that is derived from experience, is a poor guide to the future, and it is all the more important to put substantial resources into the meta-tasks of finding out how the system is changing, what tasks have become obsolete, to what extent the wisdom of experience has suddenly turned into folly, and what tasks, in the light of the rapidly changing social system, are possible and what are impossible. Without somebody to perform the meta-tasks we would still be trying to squarc the circle, invent perpetual motion, and devise the best methods for practicing magic and alchemy. In the field of social systems most of the operating agencies are still in the age of alchemy, and it is not surprising that their operations usually turn out so badly.

The meta-task, however, cannot be performed in a vacuum. The university as a meta-task agency performs best when it is independent of, but not isolated from, the operating agencies whose main function is the task itself. It must be independent or it will be swallowed up in the task itself and the meta-task will not be performed. There is real danger of this, especially in the light of the enormous pressures on the universities for applied research. Nevertheless, the university must not be isolated; it 
must be deeply involved in the society in which it is imbedded. Otherwise the task which the operating agencies are performing will remain unquestioned and the new tasks which the university is suggesting will not be carried out. We should not despise the ivory tower; for many purposes it is necessary; but we should see that it is provided with good elevator service and that there is a good vulgar TV set in every room.

One would like to see, therefore, corresponding to every operating agency and to every division of government, and for that matter to every major segment of the business world and the economy, a corresponding research agency in the university, in close contact with a research division of the operating agency itself. The research agency in the university would be free to follow the inner dynamic of science, to develop wild ideas and intellectual mutations, and also to develop rigorous means of testing reality. The research division in the operating agency will properly be more concerned with day-to-day problems, with short-run views, and with easy and inaccurate answers to difficult but pressing questions. Then one would like to see these two modes of intellectual endeavor have equal social status, so that they could establish close and constant contact with each other through the circulation of personnel, through conferences and journals, and through the establishment of a common frame of communication and discourse. It is only as we establish an interlocking chain of personal communication that the gap between the meta-task and the task can be filled. Practice must constantly be translated into theory and theory back into practice if we are to establish a cumulative process of increasing knowledge and skill.

The Center for Research on Conflict Resolution has welcomed the establishment of the Institute for Arms Control and Peace Research. The center is primarily concerned with the development, on the one hand, of both an adequate theoretical structure and reality-testing apparatus for the international system and for conflict processes in general, and an information-processing apparatus which will act as a check on our perceptions of social reality in this field. We are not equipped, nor should we be equipped, to deal with the daily problems of negotiators in Geneva or with the formulation of position papers for the State Department. Up to now, however, our lines of communication both to and from the decision-makers have been few. We particularly welcome the Institute for Arms Control and Peace Research, therefore, as an intermediary as well as an intellectual enterprise in its own right. The structure which seems to be developing at The University of Michigan, therefore, may make a unique contribution not only to the solution of the problems in which it is specifically engaged but as the possible forerunner of a general pattern of intellectual organization, in which pure research, applied research, operating research, and operations themselves are linked through a chain of agencies each of which has close contact and communication with those nearest to it. By means of this kind of intellectual organization the ivory tower can be saved from sterility and from preoccupation with unreal problems entirely of its own making, and the laborer in the dusty vineyards can be saved from the endless repetition of habitual but inefficient tasks. It may well be, therefore, that our intellectual and organizational response to this number one problem of our day, the establishment of stable peace, may have a carry-over in many other fields of human life and endeavor, and that in this generation we may hope to learn something that the human race for unnumbered ages will never want to forget. 